\title{
EDITORIAL
}

\section{THE FUTURE OF GERIATRICS}

\author{
J.E. MORLEY \\ Corresponding author: John E. Morley, MB, BCh, Division of Geriatric Medicine, Saint Louis University School of Medicine, 1402 S. Grand Blvd., M238, St. Louis, MO 63104, \\ Email: john.morley@health.slu.edu
}

Key words: Geriatric medicine, aging tsunami, population aging.

"The future is uncertain...but this uncertainty is at the very
heart of human creativity..."
Ilya Prigogine (1917-2003)

We are being asked to reframe aging and to talk of it only in positive terms. To talk of an "Aging Tsunami" is unacceptably negative. Unfortunately, this is happening at a time when geriatrics is balancing itself poorly on a precipice. As the world's population rapidly ages, the growth of geriatricians is far too slow to provide an adequate number of physician specialists to care for the needs of the older population. In the United States the number of practicing geriatricians per older adult is expected to be almost halved by 2030 since the early 1980s (From 1 for every 2546 in 1985 to 1 for every 4254 by 2030) (1). In the United Kingdom, geriatrics is the medical subspecialty with the most members. There are over 1300 geriatricians who predominantly provide in-hospital care, with little attention to community care (2). The availability of geriatricians is similar or less in the rest of the world (Figure 1).

\section{Figure 1}

Geriatricians/10,000 Population 65 Years and Over

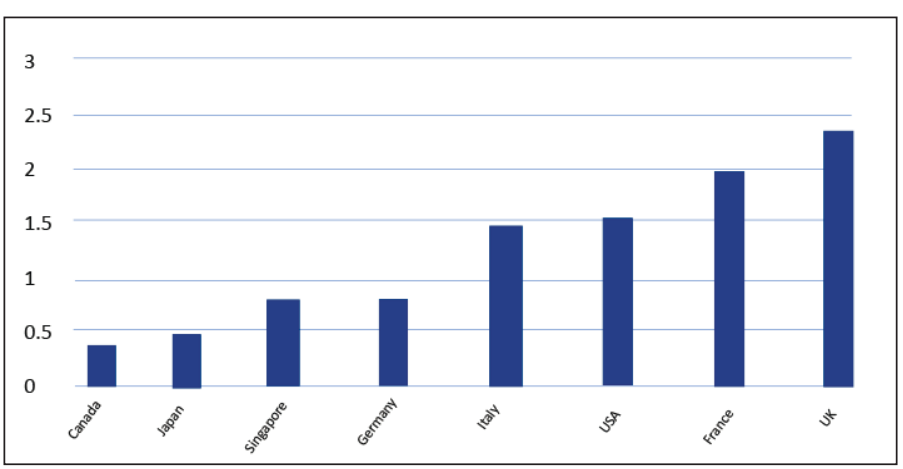

The first pediatric hospital, Hôpital des Enfants Maluides was established in Paris in 1802. By the mid twentieth century pediatric hospitals have become the norm for high quality care for children. During this time, 2 major texts on geriatric medicine by George Day (1848) and Ignatz Nascher (1914) were published, and there was a variable introduction of old age homes $(3,4)$. Marjory Warren, after working at the workhouse next to the West Middlesex County hospital, argued for the need of special units for geriatric medicine in hospitals. This led to geriatric medicine being recognized by the United Kingdom National Health Service as a medical specialty. Warren developed the principles of geriatrics which remain today the driving force of geriatric medicine:

- To prevent illness

- To reduce disability as much as possible

- To strive for maximum independence

- To educate the older person to cope with disability (5)

As we explore the roles of the modern geriatricians it involves care for older persons in multiple sites: Hospital, community, rehabilitation facilities, nursing homes and home care. While much of its original focus was on rehabilitation of disabilities as in the Geriatric Evaluation and Management Unit (6), it also spread to enhanced hospital care focused on recognizing the geriatric giants of Bernard Isaacs (7) and caring for those with delirium (8-10) and recognizing the need for deprescribing (11). In the USA, the American Medical Directors Association has made major advances in the care of older persons in nursing homes (12). More recently there has been a focus on secondary prevention to slow the development of disability. The John A. Hartford's 4Ms (what Matters? Mobility, Medications and Mobility) (13) and the World Health Organizations ICOPE (Integrated Care Older People) (14) have both set out a general concept of this approach. A more aggressive approach has been the Gerontopole in Toulouse approach to screening for frailty and cognitive impairment (15) and in the USA the Rapid Geriatric Assessment (RGA) to directly screen for and treat the modern geriatric giants (frailty, sarcopenia, anorexia of aging and cognitive dysfunction (16, 17).

Thus, one view of the future of geriatrics is that we will develop geriatric hospitals as has been done in Costa Rica (18). These would function similarly to pediatric hospitals and be the base for community programs and education of general practitioners.

While all of these should be included in the future of geriatrics we clearly do not have enough geriatricians or advanced practice nurses to do this, so at least for the near future, we need to focus on education of health professionals to improve the future care of older persons. Daniel Sommes, a London geriatrician suggests the future is "interface" (into Emergency Department, surgery, tertiary medical specialties, 


\section{THE FUTURE OF GERIATRICS}

primary care), "education" (skilling others up, we can't do it all ourselves) and "prevention" (can we (+how can we) reduce incidence of frailty, sarcopenia, etc.). The American College of Emergency Physicians want core trainee competencies in geriatrics, a survey of status quo and multi-organization endorsed guidelines. Mike Wasserman wanted effective messaging of geriatrics with appropriate reimbursement (compared to other specialists) and a requirement of geriatric competences in general medicine education. Howard Elias calls for geriatricizing subspecialties and forming combined training programs. All of the factors in this paragraph could become the future if geriatricians could be more successful and less timid in public policy (Natalia SA).

I believe most of you reading this would consider the points discussed as a part of the certainty of the future of geriatrics; but what areas can we see of uncertainty? Certainly geriatricians already focus on patient centered care and we should find it relatively easy to introduce computer driven precision medicine, e.g., geriatrics and biomarkers $(19,20)$. We already have developed a computer driven diagnosis for geriatric syndromes (RGA) together with a diagnostic and management algorithm, and with Reshma Merchant in Singapore an iPAD app. Artificial Intelligence (AI) is being shown to be as good as physicians to read retinal scans (21). AI will also play a central role in deprescribing. Over the next decade clearly these techniques will become everyday medical practice. As geriatricians we should be at the forefront of these developments.

An important component of the future of geriatrics is to maintain the human side of geriatrics. Certainly, we can expect a large amount of medicine move to telehealth. Persons with frailty and sarcopenia will need to have available to them exercise groups which can be done in centers or by telehealth (22). Cognitive Stimulation Therapy for persons with moderate dementia should be readily available (23) as should behavior therapy groups for dysphoria. Recently it has been recognized that loneliness is a major problem for older persons leading to cognitive defects, depression and frailty (Christine Droney). There is a need for the development of Circle of Friends programs to provide support for lonely persons (24). There is also a need for an increase in awareness of caregiver stress and to provide programs to reduce their distress (25).

There will be a continual increase in medications. It is essential that these medications are tested in older persons and against a known safe drug or preferably against a nonpharmaceutical therapy such as cognitive stimulation therapy for dementia and exercise for sarcopenia.

There is now an industry in trying to develop antiaging drugs. While the hype associated with these drugs is reminiscent of old fashioned "snake oil" it needs to be recognized that eventually some will have some degree of efficacy (26). The problem will be to determine what their longterm effects are - we need to be looking at 10 to 20 years of a placebo-controlled trial - not short term ( 3 months to a year) using surrogate endpoints.

As it always is when we move into the future it is necessary to realize it will be "the best of times, the worst of times" for us older adults and we will be dependent on geriatricians to make choices and explain them to us to make it just "the best of times."

Acknowledgments: I wish to thank my Twitter followers who had insightful comments. These are recognized in the text.

Disclosures: The authors declare there are no conflicts.

\section{References}

1. Health Resources and Services Administration (2017). National and Regional Projections of Supply and Demand for Geriatricians (2013-2015). https://bhw hrsa.gov/sites/default/files/bhw/health-workforcer-analysis/research/projections/ geriatricsReport51817.pdf

2. Oliver D. Temple M, Joseph F. Update on the future hospital programme. Future Hospital J. 2017;4:9-10.

3. Morley JE. Geriatrics: Highlights of the last 50 years. J Nutr Health Aging. 2019 (Dec) (In press).

4. Morley JE. A brief history of geriatrics. J Gerontol A Biol Sci Med Sci 2004;59:1132-1152.

5. Warren MW. Care of the chronic aged sick. Lancet 1946;1(6406):841-443.

6. Rubenstein LZ, Josephson KR, Wieland GD, et al. Effectiveness of a geriatric evaluation unit. A randomized clinical trial. N Engl J Med 1984;311(26):1664-1670.

7. Isaacs B. The challenge of geriatric medicine, Oxford University Press, Oxford, 1992, 244 pp. DOI: 10.1017/S0144686X00005213.

8. Inouye SK. Delirium in older persons. N Engl J Med 2006;354:1157-1165.

9. Flaherty JH, Tariq SH, Raghavan S, et al. A model for managing delirious older inpatients. J Am Geriatr Soc 2003;51:1031-1035.

10. MacLullich AM, Shenkin SD, Goodacre S, et al. The 4 'A's test for detecting delirium in acute medical patients: A diagnostic accuracy study. Health Technol Assess 2019;23:1-104.

11. Ohshima S, Hara A, Abe T, et al. Deprescribing using the guidelines for medical treatment and its safety in the elderly and changes in patient QOL and activities of daily living. Yakugaku Zasshi 2017;137:623-633.

12. Morley JE. The future history of long term care. J Am Med Dir Assoc 2007;8:553 556.

13. Fulmer T, Mate KS, Berman A. The age-friendly health system imperative. J A Geriatr Soc 2018;66:22-24.

14. Briggs AM, Araujo de Carvalho I. Actions required to implement integrated care for older people in the community using the World Health Organization's ICOPE approach: A global Delphi consensus study. PLoS One 2018;13(10:e0205533. Doi: 10.1371/journal.pone.0205533.

15. De Kerimel J, Tavassoli N, Lafont C, et al. How to manage frail older adults in the community? Proposal of a health promotion program experienced in a city of 16,638 inhabitants in France. J Frailty Aging 2018;7:120-126.

16. Morley JE. Rapid geriatric assessment: Secondary prevention to stop age-associated disability. Clin Geriatr Med 2017;33:431-440.

17. Morley JE, Little MO, Berg-Weger M. Rapid Geriatric Assessment: A tool for primary care physicians. J Am Med Dir Assoc 2017;18:195-199.

18. Morales-Martinez F. Editorial: A teaching geriatric hospital. J Nutr Health Aging 2019;23:4-8.

19. Morley JE, Anker SD. Myopenia and precision (P4) medicine. J Cachexia Sarcopenia Muscle 2017;8:857-863.

20. Vellas B, Morley JE. Editorial: Geriatrics in the 21st century. J Nutr Health Aging 2018;22:186-190.

21. Xu J, Xue K, Zhang K. Current status and future trends of clinical diagnosis via image-based deep learning. Teranostics 2019;9:7556-7565.

22. Izquierdo, Rodriguez-Mañas L, Sinclair AJ. Editorial: What is new in exercise regimes for frail older people - how does the Erasmus Vivifrail Project take us forward? J Nutr Health Aging 2016;20:736-737.

23. Morley JE, Cruz-Oliver DM. Cognitive stimulation therapy. J Am Med Dir Assoc 2014;15:689-691.

24. Pitkala KH, Jansson A, Savikko N. Older people's loneliness in clinical work. J Am Geriatr Soc 2019;67:2211-2212.

25. Egan KJ, Pinto-Bruno AC, Bighelli I, et al. Online training and support programs designed to improve mental health and reduce burden among caregivers of people with dementia: A systematic review. J Am Med Dir Assoc 2018;19:200-206.

26. Morley JE. Senolytics: The modern snake oil? J Nutr Health Aging 2019;23:490-493 